\title{
THE STUDY OF VISCOSITY-TEMPERATURE DEPENDENCE AND ACTIVATION ENERGY FOR PALM OIL AND SOYBEAN OIL
}

E. IKE

(Received 16 July 2019; Revision Accepted 26 July 2019)

\begin{abstract}
In fluid transport, precise knowledge or estimation of fluids behaviour is very necessary, for mass flow and heat transfer computations. In this study, physicochemical analysis of palm oil and soybean oil were conducted, in addition to an equation modeling the relationship between the energy (Ea) and the pre-exponential factor (A). Later, two other parameters; the Arrhenius temperature $(T)$ and Arrhenius activation temperature $\left(T^{*}\right)$ were introduced to buttress the veracity of the model used. The model is very useful in engineering since it would make for the estimation of the missing parameter value and its derivatives. The goodness of the result is strongly reinforced by the regression coefficient. The results indicate that the model which best fits the major defining parameters are logarithmic in nature. All the parameters studied showed that the two oil samples are good feed stock for biodiesel production and confirms their relevance in electric voltage transformers.
\end{abstract}

KEYWORDS: Physicochemical, Viscosity, Arrhenius Parameters, Equation Modeling, Temperature, Vegetable Oil.

\section{INTRODUCTION}

Viscosity is one of the physicochemical properties of fluids that are in demand for optimizing and designing industrial processes, especially in transport equations, nutrition, chemical, cosmetic, and pharmaceutical industries (Ouerfelli et al., 2013; Herráez et al., 2008; Irving, 1977; Benson, 1976; Dean,1987; Glasstone et al., 1941; Lee and Lee, 2001; Qunfang and Yu-Chun, 1999; Macías-Salinas et al., 2003; Belgacem, 2001; Viswanath et al., 2007; Hichri et al., 2013; Das et al., 2013; Das et al., 2012; Dallel et al., 2014; Ben HajKacem et al., 2014). The viscosity of fluids is determined both by collision among particles and by the force fields which determines interactions among molecules. The theoretical description of viscosity is therefore quite complex (Ben Haj-Kacem et al., 2014).
Hence, several models have been proposed in literature based on Eyring theory and other empirical relations that are not always applicable to a large number of mixtures (Ouerfelli et al., 2013; Herráez et al., 2008; Lee and Lee, 2001; Qunfang and Yu-Chun, 1999; Macías-Salinas et al., 2003; Belgacem, 2001). Vegetable oils are very relevant for their nutritional purposes and for several industrial products spanning across fuels, skin care products, flow measurement, heat exchange, sterilization, freezing, and numerous operations, high pressure lubricants and alkyd resins for paint (Rewolinski, 1985; Agbo et al., 1992; Kamel and Kakuda, 1992; Noureddini et al., 1992; Ibemesi, 1993; Foidl et al., 1996; Eromosole and Paschal, 2002). They are used in frying, cooking, salad dressing, shortening of pasty etc (Bakker et al., 1997). They mainly consist of lipids with some other minor

E. Ike, Department of Physics, Modibbo Adama University of Technology, P. M. B. 2076, Yola, Adamawa State, Nigeria. 
components including antioxidants, colorants, flavors and emulsifiers (Fasina et al., 2006). Some of these compounds occur naturally and some are added during the manufacturing process. The presence of hydrocarbons or mineral oils such as n-alkenes in vegetable oils has also been reported (Johnson, and Saikia, 2009). Vegetable oils act as carriers of fatsoluble vitamins (A, D, E, and $\mathrm{K}$ ) and play important sensory and functional roles in food products. They provide the most concentrated source of energy, supply essential fatty acids linoleic and linolenic acids which are precursors for important hormones, the prostaglandins and responsible for growth, provide satiety and increases the palatability of food (Atasie et al., 2009).

Previous studies (Steffe, 1992; Noureddini et al., 1992; Abramovic and Klofutar, 1998; Santos et al., 2005;Bhatia et al., 1990; Kapseu et al., 1991; Kashulines et al., 1991; Liew et al., 1991; Dandik et al., 1992; Noureddini et al., 1992; Liew et al., 1991; Dandik et al., 1992) had based on the viscosities of different oils, organic compound, water and their derivatives as a function of temperature, storage age, and intensity of light, pressure, molecular weight and density of liquid. Also it has been shown that some plants have seeds whose oils may be of immense values (Eromosele and Eromosele, 1993; Eromosele et al., 1994; Eromosele et al., 1998). It has also been well established that temperature has a strong influence on the viscosity of fluid products with viscosity generally decreasing with increase in temperature (Rao, 1999). Several researchers have reported the viscosity of vegetable oils at room temperature (Timms; 1985; Krishna, 1993; Kokini, 1993; Rao, 1999). At higher temperature, oil must have sufficient viscosity to carry loads. Hence heavier oils are used at higher temperature. Similarly, light oils are used at low ambient temperature. Studies have also been carried out on the effect of temperature on the viscosity of some vegetable oils at temperatures less than $110^{\circ} \mathrm{C}$ (Coupland and McClements, 1977; Toro-Vazquez and Infante-Guerrero, 1993; Rao, $1999)$ and at temperatures between $150-180^{\circ} \mathrm{C}$ (Miller et al., 1994).

Viscosity is the property of a fluid that determines its resistance to flow. It is an indicator of flow ability of lubricating oil and through its film strength, viscosity values are used in evaluating load carrying capacity, in denoting the effect of temperature changes and for determining the presence of contaminants in used oil during service. Absolute viscosity values are required in all ball bearing design calculations and in the technical design of other lubrication engineering.

Since the easiest experimental set-up to be used is simple shear viscosity, the dependence of the shear viscosity of a fluid with temperature has been shown to be in the general form of the Arrhenius-type though initially written by De Guzman (1913), and then developed by Eyring (1936; 1937) for numerous Newtonian classic solvents (Fasina and Colley, 2008), which can be expressed as:

In $\eta=\left(\frac{E_{a}}{R}\right) \frac{1}{T}+\operatorname{In} A$

where $R, E_{a}$, and $A$ are respectively the gas constant $\left(8.31 \mathrm{JK}^{-1} \mathrm{~mol}^{-1}\right)$, the Arrhenius activation energy, and the pre-exponential factor of the Arrhenius equation for the liquid system. There is no negative sign in front of $E_{a}$ since equation 1 is derived from viscosity and not from the rate of the phenomenon as in the original Arrhenius equation. The equation can be deduced from simple thermodynamic considerations where flow is believed to be a local transition of a molecule or a group of molecules between one state (before flowing) to another (after flow occurred) having to overcome an energy barrier (Tatiana and Patrick, 2015). One of the most common models assumes that the flow is controlled by the presence of free volume enabling molecules to jump from one place to another. Such mechanism implying a relation between free volume and viscosity was first found empirically by Batschinski (1913).

The plot of the logarithm of viscosity versus the reciprocal of absolute temperature $(1 / T)$ for numerous liquid systems is practically linear and the Arrhenius parameters, which are the activation energy $\left(E_{a}\right)$ and the pre-exponential factor $(A)$, are thus independent of temperature over the temperature ranges (from 278.15 to 328.15$) \mathrm{K}$ approximately around the room temperature at constant atmospheric pressure. Using both graphical and linear least-squares fitting methods, the slope of the straight line is equal to $\left(E_{a} / R\right)$ and the intercept on the ordinate equals 'In A'. In addition to these two main parameters, there is a third parameter called the Arrhenius temperature $\left(T_{a}\right)$ derived from the intercept with the abscissa as:

$T_{A}=\frac{-E_{a}}{R \operatorname{In} A}$

Equation (2) simplifies the viscosity-temperature dependence equation following the Eyring (Dean, 1987; Viswanath et al., 2007; Eyring, 1936; Eyring and Hirschfelder, 1937; H. Eyring and John, 1969) equation as;

In $\eta=\left(\frac{E_{a}}{R}\right)\left(\frac{1}{T}-\frac{1}{T_{A}}\right)$

3

For homogenous dimensions (Glasstone, Laidler and Eyring, 1941), we can as well calculate another parameter termed the Arrhenius activation 
temperature $\left(T^{*}\right)$ as an additional variable for other statistical investigations:

$\boldsymbol{T}^{*}=\frac{\boldsymbol{E}_{\boldsymbol{a}}}{\boldsymbol{R}}$

4

Equation 1 can be derived from the thermodynamic standpoint where the flow is seen as a local transition of a molecule or a group of molecules between one state (position before flowing) to another (position after flow occurred) having to overcome an energy barrier. One of the most common models assumes that the flow is controlled by the presence of free volume enabling molecules to jump from one place to another. Such mechanism implying a relation between free volume and viscosity was first empirically propounded by Batschinski (1913). For small molecules where forces resisting flow are mainly linked to interaction forces, there is a good correlation between activation energy (Ea) and the heat of vaporization at temperatures where there are large fractions of free volume (Vinogradov and Malkin, 1980).

The focus of the present study is to investigate the physicochemical behaviour of two samples of vegetable oil and also the dependence of their viscosities on temperature. The relationship between the viscosities of palm oil and soybean oil with temperature variations will be found by fitting equations.
METHODOLOGY

Materials: The vegetable oil is available in local supermarkets and specialty shops. All oil was stored at room temperature (at about $20{ }^{\circ} \mathrm{C}$ ) and in a dark place before the analysis. The chemicals used in cleaning or removing traces of solvent are suitable organic solvents like $\mathrm{CCl}_{4}$, ether, petroleum spirit or benzene. The apparatus used were Red Wood Viscometer, stop watch, Kohlrausch flask, thermometer, filter paper. Prior to the experiment, the oil was thoroughly filtered through a muslin cloth to remove solid particles that may clog the jet.

Methods: The viscometer was leveled with the help of leveling screws and the outer bath was filled with water for determining the viscosity at $90{ }^{\circ} \mathrm{C}$ and below. The jet was closed with a ball valve and then the test oil was poured into the cup, up to the tip of the indicator. A clean dry Kohlrausch flask was immediately placed below and directly in line with discharging jet while a clean thermometer, a stirrer was inserted into the cup and covered with a lid. The water bath was heated slowly with constant stirring and when the oil in the cup reached a certain temperature, the heating was stopped. The ball valve was lifted, the oil from the jet flows into the flask as the stop-watch was immediately engaged. The stop watch was disengaged when the lower meniscus of the oil reaches the $50 \mathrm{ml}$ mark on the neck of receiving flask as we record the time taken. The same procedures were repeated to get more readings at different temperatures. 


\section{RESULTS AND DISCUSSION}

Figures 1 to 4 indicate the obtained results from the research:

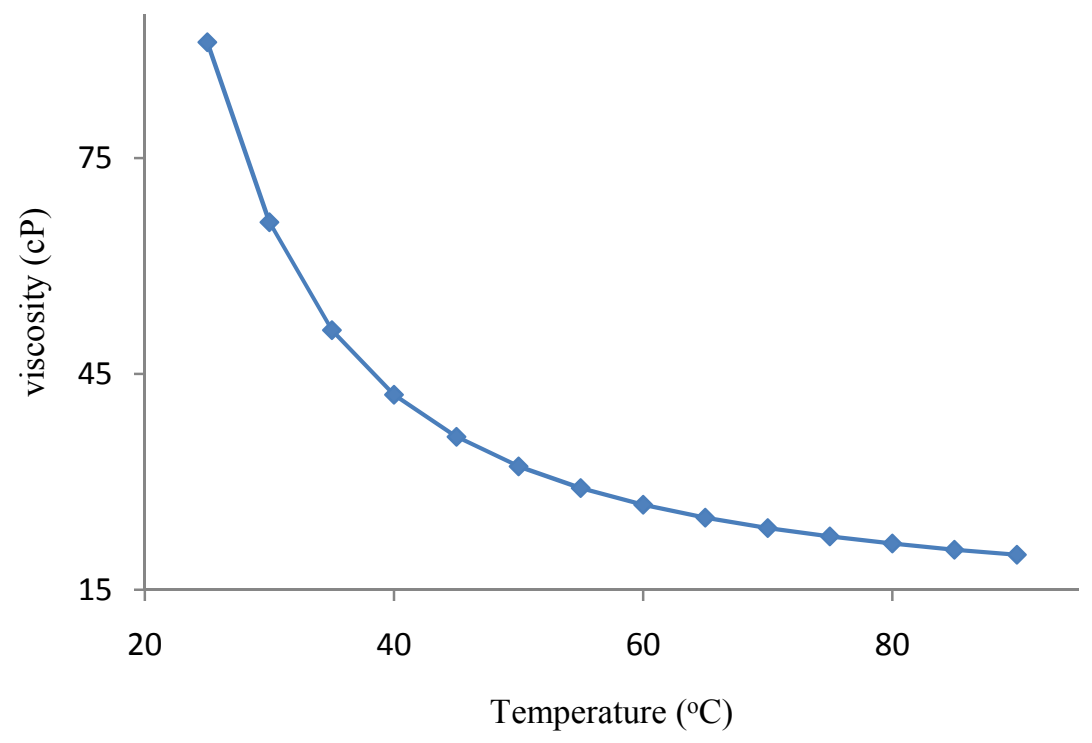

Figure 1: Variation of Viscosity (Centipoise) with Temperature $\left({ }^{\circ} \mathrm{C}\right)$ for Palm Oil

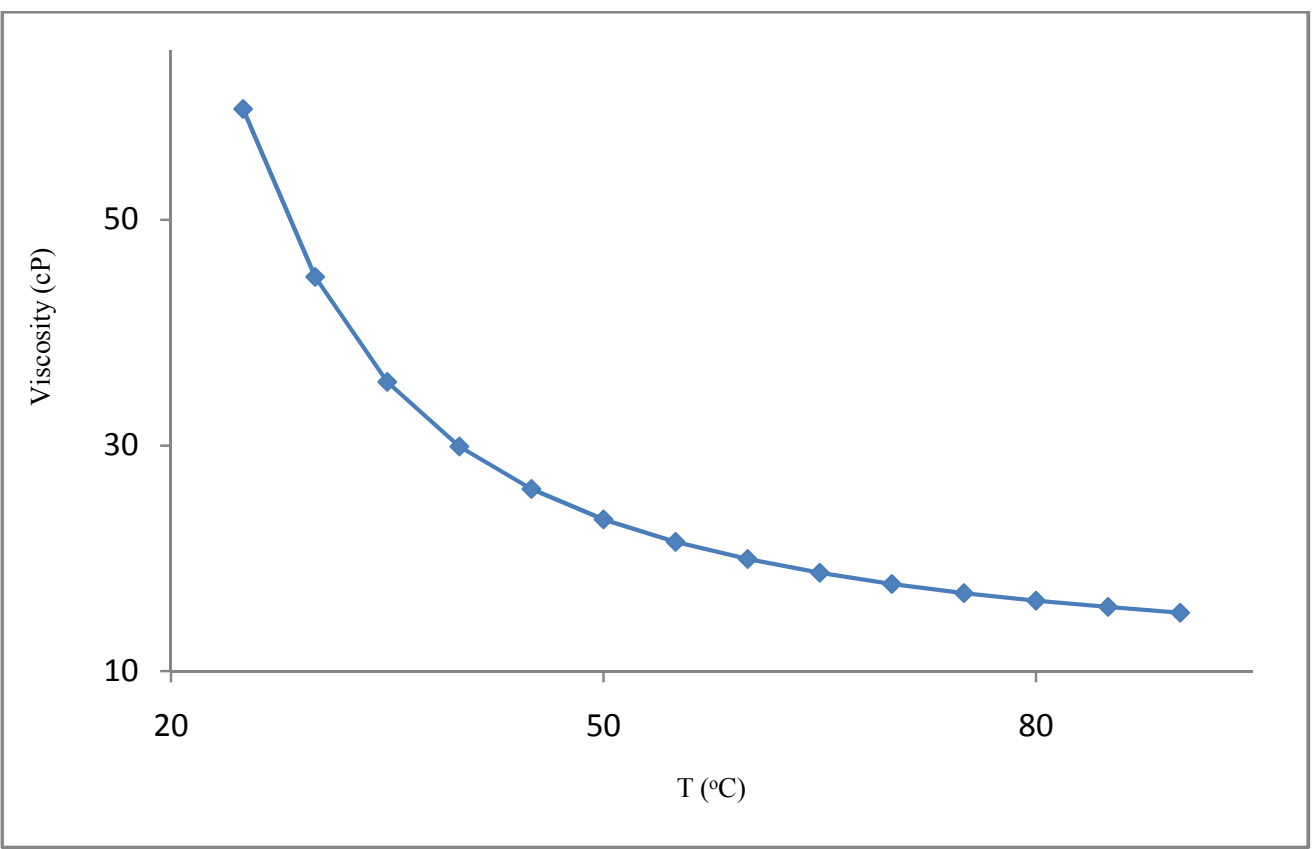

Figure 2: Variation of Viscosity (Centipoise) with Temperature $\left({ }^{\circ} \mathrm{C}\right)$ for Soybean Oil 


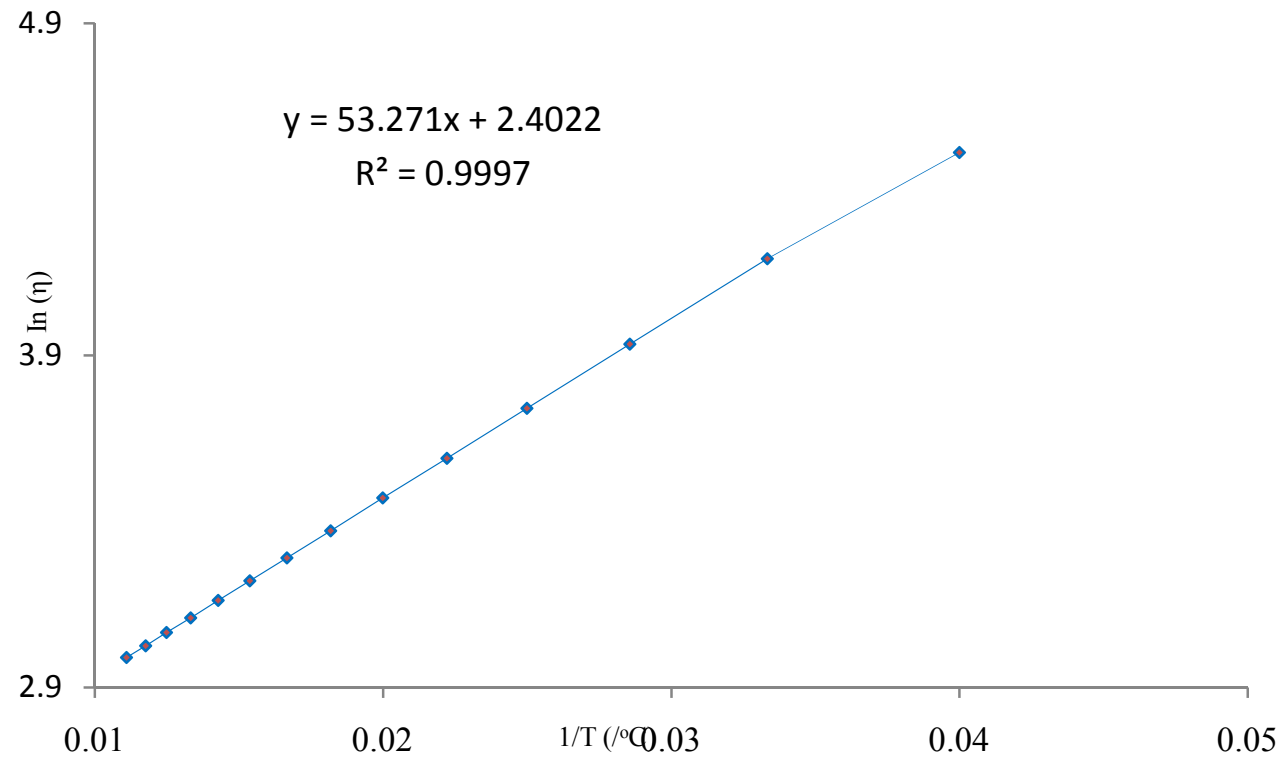

Figure 3: Natural Log of Viscosity $(\operatorname{In} \eta)$ Versus Inverse of Temperature $\left({ }^{\circ} \mathrm{C}^{-1}\right)$ for Palm Oil

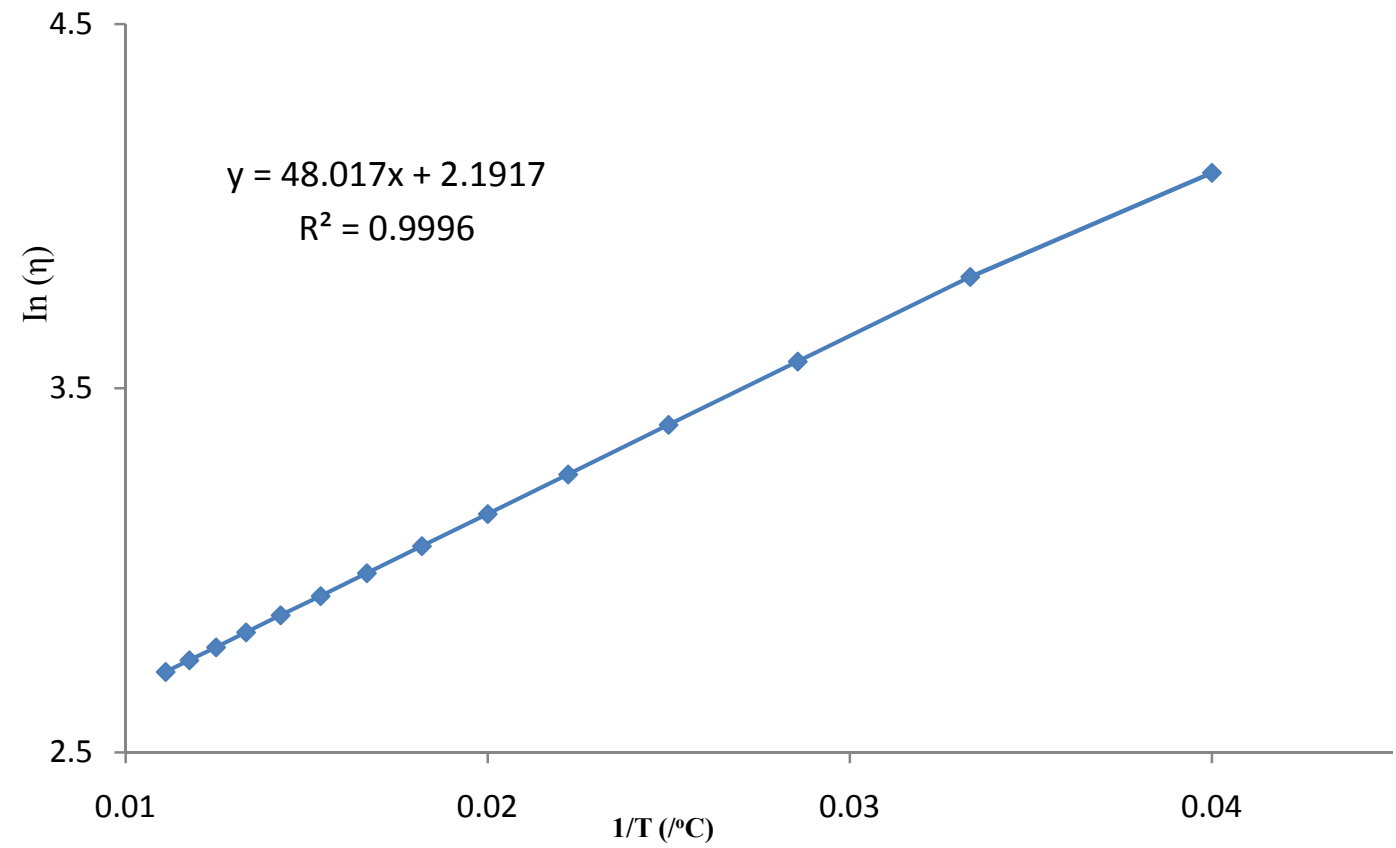

Figure 4: Natural Log of Viscosity (In $\eta$ ) Versus Inverse of Temperature $\left({ }^{\circ} \mathrm{C}^{-1}\right)$ for Soybean Oil 
As a result of increased industrial and nutritional processes, the need for oil and their close derivatives has increased culminating into the search for oils from different varieties of seeds. Hence, palm oil and soybean oil were extracted, analyzed and some of their physicochemical properties were compared. With the help of Microsoft Excel Package, rheological measurements were all conducted in the linear regime in order to estimate the Newtonian viscosity as a function of temperature, from which other relevant parameters were estimated using equations 1,2 and 4. For the palm oil, we obtained that the Activation energy $E_{a}(442.68201 \mathrm{~J} / \mathrm{mole})$, Entropic (preexponential) factor $\mathrm{A}(11.04745406 \mathrm{cP})$, Arrhenius temperature $\mathrm{T}_{\mathrm{A}}\left(-22.17592207^{\circ} \mathrm{C}\right)$ and the Arrhenius activation temperature $\mathrm{T}^{*}\left(53.271{ }^{\circ} \mathrm{C}\right)$, respectively. While the results for the soybean oil show that $399.02127 \mathrm{~J} / \mathrm{mole}, 8.950415896 \mathrm{cP},-21.90856413$ ${ }^{\circ} \mathrm{C}, 48.017^{\circ} \mathrm{C}$ we obtained respectively for the same quantities.

Figures 1 and 2 indicate the variation of viscosity with temperature; it can be observed that the viscosity decreases with increasing temperature. With an increase in temperature, there is an increase in the molecular interchange as the molecules move faster. The molecular interchange occurring in liquids is similar to what is obtained in a gas, except that there is substantial addition of cohesive forces between the molecules of a liquid unlike those of the gases. The impact of increasing the temperature of a liquid is to reduce the cohesive forces while simultaneously increasing the rate of molecular interchange. The former effect causes a decrease in the shear stress while the latter causes it to increase. The result is that liquids show a reduction in viscosity with increasing temperature while it increases in gases, with the drag force remaining the same. Its very needful to understand the influence of temperature on the viscosity of fluid, especially in engines where the lubricating oil is heated to very high temperatures due to combustion of the fuel, hence it is important to ascertain if the oil will be viscous enough to lubricate the moving parts of the engine at such temperatures. Peradventure the fluid loses its viscosity at such high temperatures; the fluid may start to evaporate. Contrarily, in refrigerating compressors, we have very low temperatures on the suction side of the compressor and high temperature on the discharge side. Therefore, any fluid to be used as lubricant should be able to maintain its viscosity at both extremes. The fluid that can sustain those operating temperatures should only be selected, otherwise the very aim of using such fluid is defeated. The coefficients of regressions for the graph of the natural log of viscosity versus reciprocal of temperature (Figures 3 and 4) for palm oil and soybean oil show
0.9997 and 0.9996 respectively. This indicates very good fit. Most importantly, the aforementioned properties of our oil samples show a linear behaviour by obeying the Arrhenius viscosity model (Equation 4) and there appears a remarkable statistical nonparametric correlation between the activation energy $\left(E_{a}\right)$ and the entropic factor $(A)$, so also the Arrhenius temperature $\left(T_{A}\right)$ for both samples.

Results showed that the model which best fits the relationship between the Arrhenius parameters is a logarithmic type correlating the activation energy $\left(E_{a}\right)$ to the Arrhenius temperature $\left(T_{A}\right)$. Concerning the hydraulic calculations of fluid transportations and for energy transfer (Aymen et al., 2015), we have reduced the model using single variable without losing significant accuracy. The equation used in the present work allows for redefining the Arrhenius equation by using a single parameter (Ben Haj-Kacem et al., 2014 and Kirkwood et al., 1949) instead of two parameters (Irving, 1977)using experimental viscosity data at several temperatures. We hereby re-emphasize that this model would be very useful in different fields of physical and chemical sciences (Ike and Ezike, 2018; Ikeand Dikko, 2018; ), especially in measuring an unknown parameter when the other quantity is available in engineering sciences (Das et al., 2012) or evaluated by some relevant theories suggested in the literature (Viswanath et al., 2007). From the results, it can be concluded that viscosity increases exponentially when the activation energy decreases. Because viscosity with small activation energy does not require much energy to reach the transition state, it should proceed faster than a reaction with larger activation energy. Also, viscosity or chemical reactions occur more rapidly at higher temperatures. This is because thermal energy controls the motion at the molecular level. As the temperature rises, molecules move faster and collide more vigorously, greatly increasing the likelihood of bond cleavages and rearrangements.

\section{CONCLUSION}

We have determined values of viscosity Arrhenius parameters such as the activation energy (Ea), entropic factor $(A)$, Arrhenius temperature $\left(T_{A}\right)$ and Arrhenius activation temperature $\left(T^{*}\right)$ for palm oil and soybean oil. Practically all of them obey the linear Arrhenius behavior. The overall results suggest some potential applications for the seed oils. From the viscosity-temperature profiles the oils can be utilized as biodiesel and lubricating oil base stock, although it may be necessary to examine their viscosities under extreme temperatures. It can be concluded from this study that temperature affects the viscosity of vegetable oils at temperatures between $25-90^{\circ} \mathrm{C}$, with 
viscosity decreasing exponentially and linearly with increase in temperature. Furthermore, a supplementary relationship between the viscosity Arrhenius parameters and the properties of numerous liquids at divers temperatures can prove how the statistical approach employed here can predict the properties of other fluid yet to be studied.

\section{REFERENCE}

Abramovic H. and Klofutar C., 1998. The Temperature Dependence of Dynamic Viscosity for Some Vegetable Oils, Acta Chimica Slovenica, Vol. 45 , No. 1, 69-77.

Agbo, N.G., Chatigre, K.O., Simard, R.E., 1992. Canariumschweinfurthii Engl: Chemical Composition of the Fruit Pulp. J. Am. Oil Chem. Soc. 69 (4), 317-320.

Atasie V, Akinhanmi T, and Ojiodu C., 2009. Proximate Analysis and Physicochemical Properties of Groundnut Arachishypogaea L. Pakistan Journal of Nutrition, Vol8, No 2, 194 $-197$.

Aymen M., Nesrine D, Hatem H., Fethi B. M. B., Yousry H. A. , Noureddine O. and Ahmed H. H., 2015. A New Equation Relating the Viscosity Arrhenius Temperature and the Activation Energy for Some Newtonian Classical Solvents. Journal of Chemistry. Vol., 2015, ID 163262.

Bakker N, P Van't, and L Zoc 1997. Adipose Fatty Acids and Cancers of the Breast, Prostate and Colon: An Ecological Study. International Journal of Cancer, Vol. 72, No. 1, 587-597.

Batschinski, A.J., 1913: Untersuchungenüber die Innerereibungder Flussigkeiten. Z. Phys. Chem. Vol. 84, 643-706.

Belgacem F. B. M., 2001. Diffusion and Drift Models for Population Dispersal from Stochastic and Continuum Views. International Journal of Applied Mathematics, Vol. 5, No. 1, 85-106

Ben Haj-Kacem R., Ouerfelli N., Herráez J., Guettari M., Hamda H., and Dallel, M., 2014. Contribution to Modeling the Viscosity Arrhenius-Type Equation for Some Solvents by Statistical Correlations Analysis. Fluid Phase Equilibria, Vol. 383, 11-20.
Benson S. W., 1976. Thermochemical Kinetics, John Wiley and Sons, New York, NY, USA, 2nd Edition.

Bhatia, V.K., Chaudhry, A., Sivasankaran, G.A., Bishi, R.P.S., Kashyap, M., 1990.Modification of Jojoba oil for Lubricant Formulations. J. Am. Oil Chem. Soc. 67 (1), 1-7.

Coupland, J.N.; Mc Clements, D.J., 1977. Physical Properties of Liquid Edible Oils. J. Am. Oil. Chem. Soc., 74, 1559-1564

Dallel M., Das D., BelHadjHmida E. S.,. Al-Omair N. A,. Al-Arfaj A. A, and Ouerfelli N., 2014. Derived Partial Molar Properties Investigations of Viscosity Arrhenius Parameters in Formamide $+\mathrm{N}, \mathrm{N}-$ Dimethylacetamide Systems at Different Temperatures. Physics and Chemistry of Liquids, Vol. 52, No. 3, 442-451.

Dandik, L., Sahin, E., Karaosmanglu, F., Isigigur, A., Aksoy, H.A., 1992. Characteristics of beechnut oil FagusovientalisLipsky of Turkish origin. J. Am. Oil Chem. Soc. 69 (12), 12741275.

Das D., Messaâdi A., Dhouibi N., Ouerfelli N., and Hamzaoui A. H., 2013. Viscosity Arrhenius Activation Energy and Derived Partial Molar Properties in N,N-Dimethylacetamide + water Binary Mixtures at Temperatures from 298.15 to $318.15 \mathrm{~K}$. Physics and Chemistry of Liquids, Vol. 51, No. 5, 677-685.

Das D., Barhoumi Z., Dhouibi N., Sanhoury M. A. M. K, and Ouerfelli N., 2012. The Reduced Redlich-Kister Equations for Correlating Volumetric and Viscometric Properties of N,NDimethylacetamide + Dimethylformamide Binary Mixtures at Temperatures from 298.15 to $318.15 \mathrm{~K}$. Physics and Chemistry of Liquids, Vol. 50, No. 6, 712-734.

Dean J. A., 1987. Handbook of Organic Chemistry, McGraw-Hill, New York, NY, USA.

De Guzmán, J., 1913: RelaciónEntre la Fluidez y el Calor de Fusion, Anales de la Sociedad Española de Fisica y Quimica, vol 11, 353362.

Eromosele, I.C., Eromosele, C.O., 1993. Studies on the Chemical Composition and Physico- 
Chemical Properties of Seeds of Some Wild Plants.Plant Foods Hum.Nutri. 43, 251-258.

Eromosele, I.C., Eromosele, C.O., Akintoye, A.O., Komolafe, T.T., 1994. Characterization of Oils and Chemical Analyses of Seeds of Wild Plants.Plant Foods Hum.Nutri. 46, 361-365.

Eromosele, I.C., Eromosele, C.O., Innazo, P., Njerim, P., 1998. Studies on Some Seeds and Seed Oils. Bioresour. Technol. 64 (3), 245- 247.

Eromosele, C.O., Okieimen, F.E., 1998. Utilization of Khaya Senegalensis Seed Oil in the Thermal Stabilization of Polyvinylchloride. J. Appl. Polym. Sci. 16, 30-40.

Eromosele C.O. and Paschal N. H., 2002. Characterization and Viscosity Parameters of Seed Oils from Wild Plants. Bioresource Technology 86, 2003 203-205.

Eyring $H_{\text {., }}$ 1936. Viscosity, Plasticity, and Diffusion as Examples of Absolute Reaction Rates. The Journal of Chemical Physics, vol. 4, no. 4, pp. 283-291, 1936.

Eyring H. and Hirschfelder J., 1937. The Theory of the Liquid State. Journal of Physical Chemistry, Vol. 41, No. 1, pp. 249-257, 1937.

Eyring H. and M. S. John M. S., 1969., Significant Liquid Structure, Wiley, New York, NY, USA..

Fasina O. O., and Z. Colley Z., 2008. Viscosity and Specific Heat of Vegetable Oils as a Function of Temperature: $35^{\circ} \mathrm{C}$ to $180^{\circ} \mathrm{C}$. International Journal of Food Properties, vol. 11, no. 4, 738- 746 .

Fasina O, Hallman C, and Clementsa, C., 2006. Predicting Temperature-Dependence Viscosity of Vegetable Oils from Fatty Acid Composition. Journal of American Oil Chemical Society, 83(3), 899-903.

Foidl, N., Foidl, G., Sanchez, M., Mittelbach, M., Hackel, S., 1996.JatrophaCurcasL. as a Source of Production of Biofuel in Nicaragua. Bioresour. Technol. 58 (1), 77-82.

Glasstone S., Laidler K. L., and Eyring H., 1941. The Theory of Rate Process, McGraw-Hill, New York, NY, USA.
Herráez J. V., R. Belda R, Díez O., and Herráez M., 2008. An Equation for the Correlation of Viscosities of Binary Mixtures. Journal of Solution Chemistry, Vol. 37, No. 2, 233-248.

Hichri M., Das D., Messaâdi A., Hmida E. S. B. H., Ouerfelli N. and Khattech I., 2013. Viscosity Arrhenius Activation Energy and Derived Partial Molar Properties in of N,NDimethylacetamide + 2-Ethoxyethanol Binary Mixtures at Temperatures from $298.15 \mathrm{~K}$ to $318.15 \mathrm{~K}$. Physics and Chemistry of Liquids, Vol. 51, No.6, 721-730.

Ibemesi, J.A., 1993. Potential of Melon Seed Oil in Development of Alkyd Resin N. J. Sci. 27, 299-304.

Ike E. and Ezike S. C., 2018. Estimation of Viscosity Arrhenius Pre-exponential Factor and Activation Energy of Some Organic Liquids. International Journal of Recent Research in Physics and Chemical Sciences (IJRRPCS) Vol. 5, No. 1, 18-26.

Ike E. and Dikko A. B., 2018. Determination of the Arrhenius Parameters of Mahogany Seed Oil using Viscosity Flow Data. International Journal of Innovative Science and Research Technology ISSN No:-2456-2165. Volume 3, No. 2, 18-26.

Irving J. B., 1977. Report Numbers 630 and 631, National Engineering Laboratory, Glasgow, UK.

Johnson S, and Saikia N. 2009. Fatty Acids Profile of Edible Oils and Fats in India. Center of Science and Environment, Vol1, No 2, 30-36.

Kamel, B.S., Kakuda, Y., 1992. Characterization of the Seed Oil and Meal From Apricot, Cherry, Nectarine, Peach and Plum. J. Am. Oil Chem. Soc. 69 (5), 492-494.

Kapseu, C., Kayem, G.J., Balesdent, D., Schuffenecker, L., 1991. The Viscosity of Cotton Seed Oil, Fractionation Solvents and Their Solutions. J. Am. Oil Chem Soc. 68 (2), 128-130.

Kashulines, P., Rizvil, S.S.H., Harriott, P., Zollweq, J. A., 1991. Viscosities of Fatty Acids and Methylated Fatty Acids Saturated with Supercritical Carbon Dioxide. J. Am. Oil Chem. Soc. 68 (12), 912- 921. 
Kirkwood G., Buff F. P., and Green M. S. 1949. The Statistical Mechanical Theory of Transport Processes. III. The Coefficients of Shear and Bulk Viscosity of Liquids. The Journal of Chemical Physics, Vol. 17, No. 10, .988-994.

Kokini, J. L. Rheological Properties of Foods, in Handbook of Food Engineering; Heldman, D.

R., Lund, D.B., Eds.; Marcel Dekker: New York, NY, 1993; 1-38.

Krishna, A.G.G. Influence of Viscosity on Wax Settling and Refining Loss in Rice Bran Oil. J. Am. Oil. Chem. Soc.1993, 70, 895-898. 11.

Lee L.-S. and Lee Y.-S (2001). The Application of the Equations of State Incorporated with Mixing Rules for Viscosity Estimations of Binary Mixtures. Fluid Phase Equilibria, Vol. 181, No. 1-2, 47-58.

Liew, K.Y., Seng, C.E., Lau, E.K., 1991. Viscosities of Some Longchain Fatty Acids and their Relationship with Chain Length. J. Am. Oil Chem. Soc. 68 (7), 488-492.

Macías-Salinas R., García-Sánchez F. and G. EliosaJiménez (2003).An Equation-of-State-Based Viscosity Model for Non-Ideal Liquid Mixtures. Fluid Phase Equilibria, Vol. 210, No. 2, 319334.

Miller, K.S.; Singh, R.P.; Farkas, B.E. Viscosity and Heat Transfer Coefficients for Canola, Corn, Palm and Soybean Oil. J. Food Process. Preserv. 1994, 18, 461-472.

Noureddini, H., Teoh, B.C., Clements, L.D., (1992). Viscosities of Vegetable Oils and Fatty Acids.J. Am. Oil Chem. Soc. 69 (12), 11891191.

Ouerfelli N, Bouaziz M, and Herráez J. V. 2013. Treatment of Herráez Equation Correlating Viscosity in Binary Liquid Mixtures Exhibiting Strictly Monotonous Distribution. Physics and Chemistry of Liquids, Vol. 51, No. 1, 55-74.
Qunfang L. and Yu-Chun H., 1999. Correlation of Viscosity of Binary Liquid Mixtures. Fluid Phase Equilibria, Vol. 154, No. 1, 153-163.

Rao, M. A. Rheology of Fluid and Semifluid Foods: Principles and Applications, Aspen Publication: Gaithersburg, MD, 1999; 433 pp. 10.

Rewolinski, C., 1985. Sunflower Oil Diesel Fuel: Lubrication System Contamination. J. Am. Oil Chem. Soc. 62 (7), 1120-1124.

Santos J. C. O, Santos I. M. G., and Souza A. G., 2005. Effect of Heating and Cooling on Rheological Parameters of Edible Vegetable Oils, Journal of Food Engineering, vol. 67, no. 4, 401-405.

Steffe J. F., 1992. Rheological Methods in Food Process Engineering, Freeman Press, East Lansing, Mich, USA,

Tatiana Budtova and Patrick Navard. 2015.ViscosityTemperature Dependence and Activation Energy of Cellulose Solutions. Special Issue: Cellulose Dissolution and Regeneration: Systems and Interactions Nordic Pulp and Paper Research Journal.Vol30,No 1.

Timms, R.E., 1985. Physical Properties of Oils and Mixtures of Oils. J. Am. Oil. Chem. Soc., 62, 241-248.

Toro-Vazquez, J.F.; Infante-Guerrero, R., 1993. Regression Models that Describe Oil Absolute Viscosity. J. Am. Oil. Chem. Soc., 70, 11151119

Vinogradov, G.V. and Malkin, Ya, A., 1980: Rheology of Polymers, Mir publishers, Moscow, 104121.

Viswanath D. S., Ghosh T. K., Prasad G. H. L., Dutt N. V. K. and Rani K. Y., 2007. Viscosity of Liquids: Theory, Estimation, Experiment, and Data, Springer, Dordrecht, The Netherlands. 